\title{
Aplikasi Sistem Informasi Pengolahan Sampah Berbasis Web pada Perumahan Grand Vista Cikarang
}

\author{
Muhammad Makmun Effendi*, Mochammad Rahmat Faisal \\ STT Pelita Bangsa \\ *Corresponding author: effendiyan@gmail.com
}

\begin{abstract}
Abstrak — Pada penelitian ini dilakukan pembuatan website administrasi pengelolaan sampah dengan menggunakan database server MySQL, pada web server Apache, dan perancangan scripting programming yang menggunakan bahasa scripting PHP yang berjalan di sistem operasi Windows. Website ini dipergunakan untuk melakukan transaksi antara pemilik rumah dan pengelola perumahan. Fasilitasfasilitas untuk user yang diberikan pada system informasi ini antara lain adalah informasi awal sebagai cara untuk menggunakan aplikasi, data pemilik masing-masing pemilik rumah, pemasukan atau pembayaran yang dilakukan oleh pemilik rumah kepada pengelola, pengeluaran dana yang dilakukan pengelola. Aplikasi sistem ini dijalankan pada server lokal yang artinya tidak dilakukan hosting terhadap aplikasi web ini.
\end{abstract}

\section{PENDAHULUAN}

Pengelolaan keuangan menjadi hal yang sangat riskan. Mulai dari data keuangan yang hilang, atau keakuratan data yang sangat rendah. Kehilangan sebuah data menjadi satu kesalahan utama yang paling ingin dihindari. Pembukuan data secara detail memudahkan pula dalam melakukan pencarian saat dibutuhkan.

Dengan adanya kasus seperti diatas, maka dibuatlah suatu program yang berjalan di Web Browser dengan menggunaan MySQL sebagai server databasenya dan PHP sebagai Bahasa
Scriptingnya. Tujuan nya adalah untuk memudahkan user yang nantinya akan melakukan masukan, perubahan dan pengeluaran data pengelolaan keuangan sampah.

Latar belakang digunakannya MySQL sebagai server database yang utama karena MySQL cukup cepat dan sangat banyak library serta contoh program yang dapat digunakan. MySQL juga memiliki beberapa lapisan sekuritas seperti level subnetmask, nama host, dan user. Untuk query yang dilakukan oleh single user kecepatan query MySQL bisa sepuluh kali lebih cepat daripada Postgresql dan lima kali lebih cepat dibandingkan InterBase. Untuk scripting, dipilih PHP yang memang didesain untuk penulisan aplikasi web. Lebih jauh lagi akses database adalah salah satu kekuatan terbesar dari PHP jadi pilihan cocok untuk aplikasi web yang berhubungan dengan MySQL.

\section{TEORI DASAR}

\subsection{Web Server Apache}

Web server adalah inti dari sebuah web hosting, kehandalan Apache telah lama di-buktikan di Internet, versi terakhir yang stabil adalah apache1.3.17. Untuk keperlu-an secure web masih bisa ditambah modssl-2.7.1. Secure web adalah web server dengan sistem komunikasi yang dienkrip meng-gunakan protokol httpsdi port 443, analoginya seperti komunikasi ssh dibandingkan dengan telnet. Sistem enkripsinya lebih rumit daripada SSH karena selain hal teknis yang lebih rumit juga melibatkan aspek non teknis seperti Certificate Authority (CA).

Server side scripting atau CGI (Common Gateway Interface) yang biasa dipakai pada Apache adalah PHP (PHP Hypertext Prepocessor), versi terakhir yang stabil adalah 4.0.4pl1 dengan banyak kelebihan dibanding versi stabil 
sebelumnya. Dan CGI yang digunakan untuk penelitian ini adalah PHP-4.0.4pl1.

\subsection{PHP Programming Language}

PHP adalah bahasa scripting yang menyediakan cara yang mudah dalam melekatkan program pada halaman web. Karena suatu halaman diproses terlebih dahulu oleh PHP sebelum dikirim ke client, maka script dapat menghasilkan isi halaman yang dinamis, seperti misalnya menampilkan hasil query dari MySQL pada halaman tersebut. PHP pada mulanya berarti Personal Home Page, tetapi sekarang telah meng-gunakan nama "PHP Hypertext Preprocessor".

PHP banyak didukung oleh beberapa platform, banyak yang dari UNIX dan turunannya dan tentu juga Microsoft operating system yang mendukung ling-kungan dalam Win32.

Kelebihan-kelebihan PHP :

- PHP dapat digunakan untuk menghasilkan file gambar GIF, atau bahkan gambar GIF yang bersifat stream dari server ke browser. Sebelumnya harus dikompile PHP dengan GD library yang mengandung fungsi - fungsi manipulasi GIF.

- PHP mampu menerima file upload dari setiap browser yang RFc-1867 compliant. Kemampuan ini memungkinkan user mengupload file teks atau binary.

- PHP secara transparan mendukung HTTP cookie. Administrator dapat menset cookies mengunakan function setcookie().

- PHP mendukung banyak sekali database dalam mode native dan melalui ODBC. Seperti termasuk Adabas, dBase, Empress, FilePro, Informix, InterBase, MySQL, Oracle, dan database yang mensupport ODBCyang dapat menggunakan PHP

\subsection{Database Server MySQL}

MySQL adalah sebuah "SQL client/ server relational database management system" yang berasal dari Scandinavia. Pada MySQL sudah termasuk SQL server, program client untuk mengakses server, hal-hal yang berguna dalam hal administrasi, dan sebuah "programming interface" untuk menulis program sendiri.
MySQL bukan sebuah project yang open client source karena dalam keadaan tertentu diperlukan "license". Tetapi kepopuleran Web Server dari MySQL terus berkembang dalam (Apache) komunitas open source karena melisensi CGI HTML Request kannya tidak terlalu sulit (PHP) Java MySQL juga dapat berjalan pada personal komputer (banyak pengembangan dari HTTP server MySQL terjadi pada system yang tidak mahal yaitu Linux System). Tetapi MySQL juga portable dan dapat berjalan pada system www operasi yang komersial seperti misalnya Windows, Solaris, Irix.

\section{DESAIN DAN IMPLEMENTASI}

Website komputeronline.com dirancang menggunakan web server Apache, server database MySQL, dan bahasa scripting PHP. Secara garis besar, hubungan antara client browser, web server, dan database server dapat dilihat pada Gambar 1.

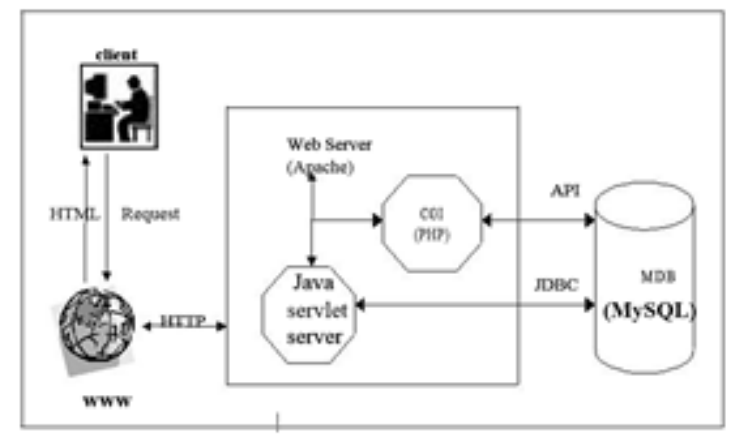

Gambar 1. Sistem Arsitektur

\subsection{Persiapan Server}

Hal-hal yang harus terdapat dan di konfigurasikan pada server agar web database dapat dibuat dengan baik adalah sebagai berikut:

- Instalasi Apache web server, digunakan versi apache-1.3.19

- Instalasi MySQL database server, digunakan versi mysql-3.23.34

- Konfigurasi pada PHP agar terhubung dengan Apache dan dapat mengakses database MySQL

- Restart Apache untuk dapat mereload modul PHP yang telah dikompilasi.

3.2 Interface User

Ada beberapa fitur yang ada di dalam system ini, diantaranya :

a. Login Aplikasi 
IT FOR SOCIETY, Vol. 03, No. 01

ISSN 2503-2224

Login aplikasi bisa dilakukan oleh 2 session yang itu user dan admin. User adalah orang yang nantinya akan mengelola semua data yang ada diaplikasi dan sementara Admin adalah orang yang nantinya akan mengelola semua data diaplikasi serta bisa melakukan maintenance terhadap aplikasi.

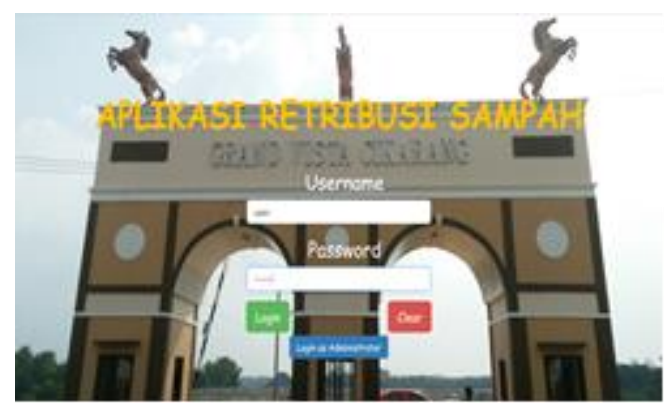

b. Dashboard

Halaman ini digunakan untuk informasi cara menggunakan user terhadap apa yang bisa dilakukan terhadap aplikasi.

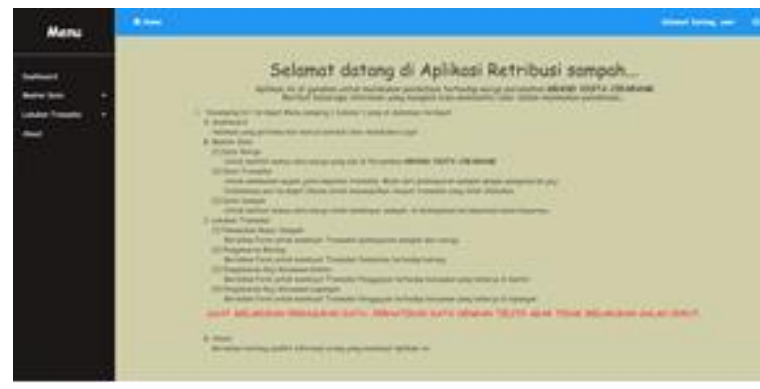

c. Master Data Warga

Halaman ini digunakan untuk infomasi seluruh data warga perumahan yang ada di Grand Vista Cikarang.

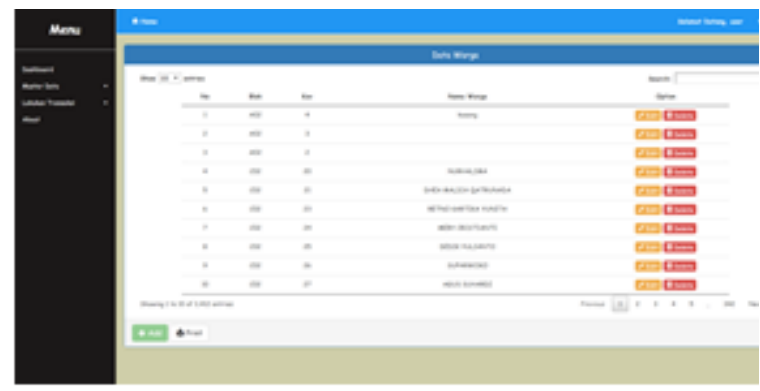

d. Pemasukan bayar sampah

Halaman ini digunakan untuk melakukan input data pemasukan uang yang dibayarkan dari pihak pemilik rumah terhadap pemilik perumahan.

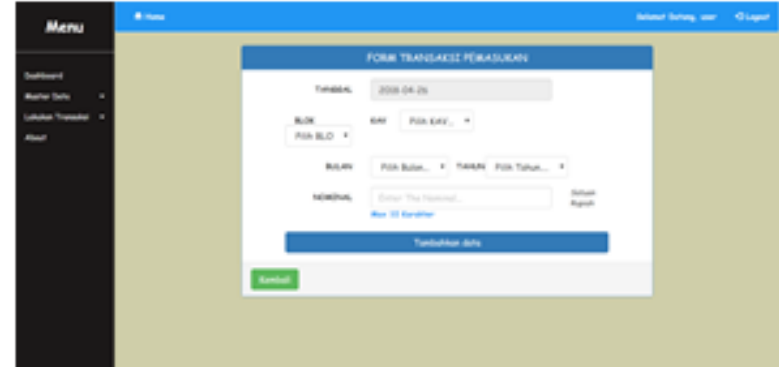

e. Pengeluaran dana dari sampah

Halaman ini digunakan untuk melakukan pelaporan tentang dana apa saja yang telah dikeluarkan untuk kepentingan persampahan yang ada di Grand Vista Cikarang.

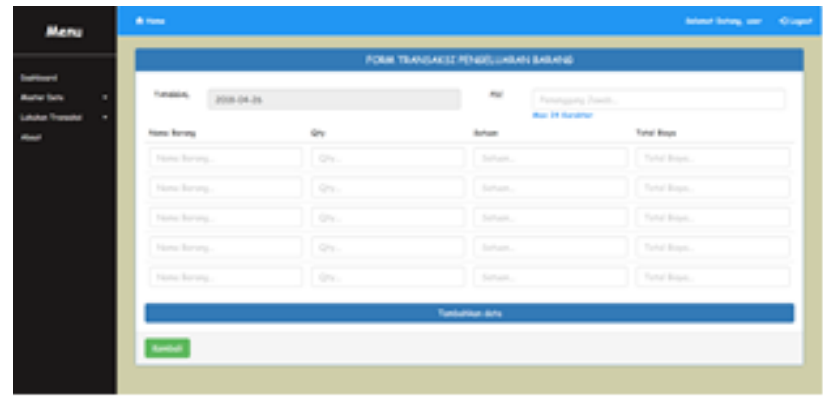

\section{KESIMPULAN}

1. Keistimewaan dari rancangan aplikasi pada pengelolaan sampah yaitu semua data pemasukan dan pengeluaran terekam atau terecord dengan baik sesuai yang dibutuhkan tanpa ada nya kendala.

2. Interface yang digunakan membantu user dalam melakukan penginputan data, karena dirancang mudah dipahami.

3. Output untuk laporanpun bisa di download ke dalam bentuk Excel, jadi bila suatu saat pimpinan ingin melihat data secara nyata, bisa di export ke Excel dan langsung di print

\section{DAFTAR PUSTAKA}

1. Castagnetto, Jesus. Professional PHP Programming. Birmingham: Wrox Press, 1999

2. DuBois, Paul. MySQL. Indianapolis: New Riders, 2000.

3. Purbo, Onno W. Membangun Web ECommerce. Jakarta: Elex Media Kompu-tindo, 2000.

4. Rahardjo, Alex Suryo, Membangun Database dengan MySQL sebagai Data-base Server pada 
IT FOR SOCIETY, Vol. 03, No. 01

ISSN 2503-2224

Website E-commerce Komputeronline.com, Universitas Kristen Petra, 2001.

5. Wiryana, I Made. Info Linux, jilid 1. Jakarta: Info Linux Media Utama, 2001.

6. __ Info Linux, jilid 3. Jakarta: Info Linux Media Utama, 2001.

7. http://www.mysql.com

8. http://www.php.net

9. http://www.wrox.com 